\title{
Methamphetamine Measurement
}

National Cancer Institute

\section{Source}

National Cancer Institute. Methamphetamine Measurement. NCI Thesaurus. Code C75348.

The determination of the amount of methamphetamine present in a sample. 